PUBLIC R\&D FUNDING:

DOES THE SOURCE DETERMINE THE STRATEGY?

\author{
Cristina Bayona Sáez \\ Universidad Pública de Navarra \\ Claudio Cruz-Cázares* \\ University of Barcelona \\ Teresa García-Marco* \\ Universidad Pública de Navarra
}

Corresponding author:

Cristina Bayona Sáez

Universidad Pública de Navarra

Departamento de Gestión de Empresas

Campus de Arrosadía s/n

Tel. 948169405

Fax: 948169404

Email: bayona@unavarra.es

* The authors wish to acknowledge funding for this paper from the Government of Navarra through a research project. Cristina Bayona-Sáez is grateful for funding through the Spanish Ministry of Science and Technology (SEC2007-67737C03-02/ECON) and Teresa García-Marco is grateful for funding throuhg the Spanish Ministry of Science and Technology (SEJ2007-67895-C04-01 y SEJ2006-09401). 


\title{
PUBLIC R\&D FUNDING: DOES THE SOURCE DETERMINE THE STRATEGY?
}

\begin{abstract}
:
The aim of this study is to analyze whether the receipt of public funding for innovation determines for present and future a firm's choice of R\&D strategy. We consider three R\&D strategies: make R\&D in-house, buy R\&D and, combined make-buy R\&D. The analysis uses a sample of 457 large firms for the period 1992-2005, taken from the Spanish Survey of Business Strategies. Estimation of a multinomial logit model with random effects shows that the positive effect of public funding varies according to the source of the aid, so, while State and Regional funds have a long term effect, other financial aid (such as EU grants) has only short-term effect. The second relevant finding is that the source of the aid also influences whether the firm selects the make, buy or make-buy strategies.
\end{abstract}

Keywords: R\&D Strategy, Public Financial Aid; Multinomial logit, Panel Data 


\section{Introduction}

Public policies on innovation play an essential role in the long-term growth and prosperity of any region. Public administrative bodies have designed a wide range of mechanisms to promote innovation in firms as a mean to correct the market failures typically associated with innovation. Different levels of government put great effort into implementing measures to improve the economic performance of the firms and other social objectives under their jurisdiction. However, as recent papers have reported, ${ }^{1}$ the discussion has become focused on the need to assess the effectiveness of these measures.

Most of the research on the effectiveness of public intervention is based on the concept of additionality (Luukkonen 2000), that is, measuring the extent to which public intervention gives rise to a new activity or outcome that would not otherwise have come into being. Most of this work adopts one of three analytic approaches: the influence of policies on $R \& D$ input levels (Branstetter and Sakakibara 1998; Almus and Czarnitzki 2003; García-Quevedo 2004), the influence on innovation behaviour (Huggins 2001; Polt and Streicher 2005; OECD 2006) and the influence on the outcome of the innovation process (Branstetter and Sakkibara 1998; Klette and Moen 1999; Huggins 2001; Benfratello and Sembenelli 2002; Bayona-Sáez and García-Marco 2010).

Against this background, this paper sets out with the main purpose of shedding some light on the effect of public R\&D support policies by evaluating additionality through behaviour indicators. There has been little research on issues as crucial as how to tell whether government fund influences the type of $R \& D$ undertaken by firms, or the way $R \& D$ is carried out or whether the support generates long-term research or simply has a one-off effect (Georghiou and Clarysse 2006). In this sense, we aim at answering whether public funding influences the R\&D strategy selection, assuming three possible

\footnotetext{
${ }^{1}$ Georghiou and Roessner (2000); Klette, Moen and Griliches (2000); Luukkonen (2000); Salter and Martín (2001); Jaffe (2002) Almus and Czarnitzki (2003); Roper et al. (2004) OECD (2006); Bayona-Saéz and García-Marco (2010) among others
} 
strategies: in-house R\&D (make), outsourced R\&D (buy), or the combination of both (make-buy). This issue is particularly important because, as previous literature has shown, each strategy has different effects on the innovation outcome.. Previous evidence appears to suggest that the buy strategy is a less effective driver of innovation, and sometimes has a negative influence on firm innovativeness . According to the evidence analyzed in this paper, however, the make strategy has a positive impact on innovation output, while the make-buy strategy seems to generate the best innovative results (Veugelers and Cassiman 2006, Cruz-Cazares, Bayona-Sáez and García-Marco 2010) Therefore, it is crucial for policy makers to evaluate whether the public funds foster the correct strategy according to the objectives pursued.

The contribution of this study is twofold. First, while a large proportion of the research focuses on a particular country or region and a specific public initiative, there have been few attempts performing simultaneous analysis of the additionality effect that fund coming from different government levels has on innovation behaviour This paper, in contrast, studies the effect that funds from Regional governments, State and other sources, including the European Union have on Spanish firms. We consider important to evaluate the behavioural effect of different public funds in the R\&D strategy selection as innovations are the main source of social and economical wealth (Baumol, 2002).

Second, methodologically, the related literature is often based on case studies or interviews with firms, or the results come from cross-sectional and relatively small samples Our contribution in this respect is to use a panel data set for the 1992-2005 period containing information on 457 Spanish firms with over 200 workers. The data were drawn from the Encuesta de Estrategias Empresariales (Business Strategy Survey). Furthermore, the technique used, multinomial logit model with random 
effects, allows us to overcome endogeneity problems and control for the unobserved heterogeneity, obtaining a more accurate approximation, and drawing causal inferences.

The paper is structured as follows. The next section describes the theoretical framework and the different types of funding available to Spanish firms and briefly presents the evidence on the repercussions of different $R \& D$ strategies on innovation behaviour. Section 3 describes the database, variables and methodology issues. The results are discussed in section 4 , and the main conclusions are summarized in the final section.

\section{Theoretical framework}

\subsection{Public R\&D funding and the behaviour perspective: a review of the literature}

The proliferation of public initiatives to support innovation has stimulated interest in assessing its effectiveness. The effect of public innovation policies on business is usually analyzed through three different perspectives: the impact on R\&D inputs, innovation behaviour and the output achievement. .

The most thoroughly investigated aspect is the impact of public funding for $R \& D$ expenditures . Research has been conducted at sector, region and business level using a variety of methods. Among the many findings, some cases have showed complementarity and others substitution between public and private funds. An exhaustive review of the related literature can be found in David, Bronwyn and Toole (2000), García-Quevedo (2004) and Lööf and Hesmati (2005).

From an output perspective the existing literature is also patently diverse both in terms of the findings and the output measures used. A survey of this research is reported in Klette, Moen and Griliches (2000), which is an analysis of evaluative studies of the effect of various public initiatives on a number of firm performance measures, such as sales growth, investment in physical assets, return over assets or sales, labour productivity, and factor productivity growth. 
This paper focuses on the third of these perspectives: innovation behaviour, aiming to explore the effect of three different public $R \& D$ funding as drivers of the $R \& D$ strategy selection. In this respect, additionality in behaviour is defined as the differences taking place in the firm's innovation behaviour after receiving public funding. This is the least common approach in econometric studies dealing with the effects of public R\&D funding. However, for politicians attempting to compare the effectiveness of different policy instruments, it will be useful to see how the government program has affected firms' R\&D behaviour and management.

Most of the studies on additionality in behaviour are based on firm-survey responses (see Polt and Streicher 2005; and OECD 2006). Many of the cited firms state that without public funding some projects would never have got underway, or at least not on the same scale or at the same speed. The surveyed firms also claim to have acquired skills and competencies that can be exploited in future innovation projects, and also to have strengthened their networks and collaboration with other firms (Georghiou and Clarysse 2006).

Specifically, some of the studies listed in the OECD publication, such as Australian Department of Industry, Tourism and Resources (2006), have found that those firms that had received a government subsidy had increased their R\&D commitment, carried out larger-scale projects requiring consultants (R\&D outsourcing), and had developed a more rigorous, well-planned R\&D management method Falk (2006) stresses that participation in a government-funded initiative helped firms to increase their R\&D skills, allowing them to take on new projects in the future. The Austrian firms surveyed by Steyer (2006) modify their R\&D strategy: they increased the percentage of their outsourcing R\&D expenditure from $10 \%$ to $22 \%$ in four years. Hyvärinen (2006) observed that Finnish firms receiving public funding engaged in higher-risk and longer-term projects, and increased their R\&D capacity through more highly skilled personnel.

\subsection{Public innovation support programs for Spanish firms}


In the Spanish context, there are three sources to which firms can apply for aid; Regional (Autonomous Community) governments, the State and other public authorities, including the European Union. The different levels serve different objectives, so it is likely that the impact of the funding will vary with the source.

Some of the state funding programs have existed over 20 years $^{2}$. Various initiatives have coexisted in Spain, with a range of objectives including the promotion of basic and precompetitive research as part of the National R\&D Plan, which calls for sustained in-house R\&D and has sometimes resulted in collaboration between firms and universities or research centres. There have also been initiatives on the part of the Ministry of Industry and Energy to encourage innovation, technological development and the incorporation of advanced technology into the industrial fabric (Acosta and Modrego 2001). This funding is aimed at growing markets and enabling firms to compete technologically (Heijs et al. 2005).

The range of Regional governments programs is very wide and very difficult to generalize. Nevertheless, some studies (Blanes and Busom 2004) report that the selection criteria for funding is not very strict, but their predominant target are SMEs . This Regional funding sometimes tends to favour firms in shrinking markets (Heijs et al. 2005) and provides a full range of support and beneficiaries firms are less experienced or less active in innovation than the type of firm targeted by State funding.

Finally, a feature that distinguishes the European funding from those described above is that they require mandatory developing in-house $R \& D$ since only purchasing or outsourcing $R \& D$ is not allowed. When collaborating, the European programs demand that the participant firms should be from a least two different EU countries. In other words, EU funding is intended for cooperative, international research, something which is more feasible for larger firms. The European funds focus on

\footnotetext{
${ }^{2}$ In fact, the first National R\&D Plan ran from 1988 to 1991 and each three years a the Plan is rebuilt according to the new technological demands.
} 
frontier technology in basic R\&D projects; the requirements are formal and the candidates are leading firms with sufficient technological skills to ensure the technological success of the projects (Heijs et al. 2005). Firms with high innovation capability usually are the receipt of these funds.

\subsection{R\&D strategy selection and innovation performance}

R\&D strategy aims to guide the firm in acquiring, developing and applying technology to generate a competitive advantage. Therefore, firms have to select the strategy best suited to their technological requirements. Traditionally, studies have analyzed three R\&D strategies commonly called make, buy and, the combination of both, make-buy. As described in some papers, each of them has its advantages and disadvantages (Veugelers and Cassiman 1999; Cho and Yu 2000; Mol 2005).

Theoretical arguments indicate that the buy strategy outperforms the make strategy since it allows risk calculation a priori, offers solutions to capacity problems and increases the speed to access to new knowledge (West, 2002). Nevertheless, it implies high transactional cost, high risk of opportunistic behaviour, external dependences and coordination problems that might reduce its impact on firm innovativeness (Kotable and Hensen 1999; Narula 2001). On the other hand, in-house R\&D facilitates the information flow between the involved departments, constitutes a unique source of knowledge, allows an objective valuation of the problems and reduces transaction costs (West, 2002). Perrons and Platts (2004) argue that the make strategy is more risky and results are less predictable and the firm could remain isolated in one specific technology.

Empirical evidence shows that the buy strategy usually has negative effects on product and process innovations (Kessler, Bierly and Gopalakrishnan 2000; Lanctot and Swan 2000; Jones, Lanctot and Teegen 2001; Fey and Birkinshaw 2005). However, some others studies found positive effects of outsourced $\mathrm{R} \& \mathrm{D}$ on product innovation but the make strategy presented a higher impact (Chen and Yuan 2007; Haro-Domínguez et al. 2007; Santamaría, Nieto and Barge-Gil 2009) 
The open innovation and absorptive capacity approaches stress that combining internal and external creates synergies that ends with a better innovative performance rather than solely making of buying. The open innovation approach indicates that due to the complexity of current products it is no feasible to develop everything in-house and argues that the main innovations come from the combination of internal and external knowledge (Chesbrough 2003). On the other hand, Cohen and Levinthal (1989) defend the idea that a firm is not able to assimilate and integrate external knowledge if it does not have the absorptive capacity gained through the internal R\&D. Empirical evidence is not conclusive since Schmiedeberg (2008) did not observed better performance of the make-buy strategy and Tsai and Wang's (2009) results through a negative effect but on the other hand, Veugelers and Cassiman (2006) and Cruz-Cázares, Bayona-Sáez and Garcia-Marco (2010) found that the make-buy strategy produces a better innovative performance.

In a broad consensus, it seems that the buy strategy produces the lower innovative results and that the make strategy outperformers the buy strategy. Theoretically, and supported with some empirical evidence, it is supposed that combining in-house and external R\&D is the best R\&D strategy. Therefore, we consider crucial to observe whether, for the Spanish case, the public R\&D funds encourage firms to select those strategies with a larger effect on firm innovativeness.

\section{Database, variables and methodology}

The Spanish Business Strategy Survey (henceforth SBSS) used in our empirical analysis is a firm-level panel dataset of manufacturing firms covering the period from 1990 to 2005 . The survey is compiled by the Ministry of Science and Technology and the Public Enterprise Foundation (FUNEP). It is random and stratified by industry sector and firm size (Fariñas and Jaumandreu 2000). It provides information on markets, customers, products, employment, outcome results, corporate strategy, human resources and technological activities. The aim of the SBSS is to document the evolution of the 
characteristics of Spanish firms and the strategies they use. For the purposes of our analysis we have selected the data pertaining to large firms with over 200 workers.

We selected large firms since several studies have found that large firms are the principal ones in receiving public R\&D funding (Wallsten 2000; Lach 2002; Czarnitzki and Hussinger 2004; Madrid and García 2009). In fact, in SBSS sample the percentage of medium and small firms receiving public R\&D funding is very low, (2.07\% and 9.2\%, respectively). According Blanes and Busom (2004) and Czarnitzki and Hussinger (2004), large firms receive more funding because they are more willing to undertake innovations projects since they can afford the fix costs associated to those projects. Additionally, they are more prone to apply for public funding as they have larger organizational resources to face the bureaucracy and paperwork inherent to the process when requesting the public funds (Czarnitzki and Hussinger 2004). Moreover, some public administrations might prefer to support large firms as they believe that their projects have more possibilities of success (Blanes and Busom 2004).

The final sample comprises 3941 observations for 457 firms, 72 of which (16\%) presented a complete panel ${ }^{3} .72 .36 \%$ of these 457 firms performed some sort of R\&D in at least one year of the period considered, from which $50.11 \%$ had adopted the make strategy, $39.37 \%$ ) the make-buy ; and $10.52 \%$ the buy strategy.

R\&D strategy (RD_ST), which is the dependent variable in the model, is defined in terms of four levels: $1=$ no $R \& D, 2=$ make, $3=$ buy and $4=$ make-buy. This is a categorical unordered variable, taken directly from the SBSS representing activities at time $t$. Firms were asked to answer the following question: Mark below if your firm performed in-house, outsourced $R \& D$ or combined both. The different levels are, by definition, mutually exclusive. Following Parmigiani (2007), in order to

\footnotetext{
${ }^{3}$ The panel data is not balanced since some firms ceased to provide information and some others were added. Due to the availability of information, our sample covers the period from 1992 to 2005 . Firms included in the final sample had to be in the panel for at least four consecutive years.
} 
ensure that the make-buy strategy truly represents the combination of both strategies, it was recoded from the original data as follows: firms that had opted for make-buy and had assigned less than $10 \%$ of their total $\mathrm{R} \& \mathrm{D}$ expenditure to outsourced $\mathrm{R} \& \mathrm{D}$ at time $t$, were recoded as adopters of the make strategy; the same less than $10 \%$ criterion was applied to in-house R\&D expenditure. Firms whose inhouse and outsourced $R \& D$ expenditures were both greater than $10 \%$ of the total remained within the make-buy category.

We have three independent variables which capture each of the public R\&D funding: the Neperian log of R\&D funding, Regional funding $(R F)$, State funding $(S F)$ and funding from other levels of governance, including the European Union $(O F)$. These variables were calculated as the Neperian $\log$ of $R \& D$ funding and are included in the model at $t, t-1$ and $t-2$ aiming to determine whether the receipt of funding has a long- or short-term effect in determining the R\&D strategy selection.

The first control variable is human capital which is measured as the percentage of engineers and graduates among the total number of workers $(G P)$. It is one of firm's internal resources that will influence its capacity to design and implement R\&D projects (Blanes and Busom 2004) and whether the R\&D can be performed in-house, using ideas proposed and developed by the firm's own employees and could also facilitate the acquisition and assimilation of external knowledge.

The second control variable is the technological intensity which captures whether firms belong to a sector with high (HTI), medium (MTI) or low technological intensity (LTI). This variable was recoded as in the SBSS the industrial sector variable is divided into 20 different industries based CNAE-93 classification.

The remaining control variables are age $\left(A G E_{t}\right)$, and firm size $(S I Z E)$. The first one captures demographic organizational characteristics such as leadership capacity, entrepreneurship, etc... and derived from the difference between the year the firm was founded and time $t$. Firm size was 
calculated from the Neperian log of total turnover. All control variables were included in the model, presented below, at time $t$ and time dummies representing each year of the data are also included

$$
\begin{aligned}
R D S_{i t}= & \beta_{1} R F_{i t}+\beta_{2} R F_{i t-1}+\beta_{3} R F_{i t-2}+\beta_{4} S F_{i t}+\beta_{5} S F_{i t-1}+\beta_{6} S F_{i t-2}+\beta_{7} O F_{i t}+\beta_{8} O F_{i t-1}+\beta_{9} O F_{i t-2}+\beta_{10} G P_{i t}+\beta_{11} \\
\text { Size }_{i t}+\beta_{12} \text { Age }_{i t}+\beta_{13} M T I_{i t}+\beta_{14} H T T_{i t}+\gamma_{i}+\varepsilon_{i t} & \text { (1) }
\end{aligned}
$$

The panel structure of the sample allows the use of panel data estimation techniques. Although observations tend to be correlated, the problem can be solved by introducing random effects. In our case, the appropriate model is the multinomial logit model with random effects, which has the advantage of allowing for control of unobserved heterogeneity and stronger causal inference (Hsiao 1985).

The model is estimated using gllamm, a Stata ${ }^{4}$ module for maximum likelihood estimation of generalized linear latent and mixed models. This software has the capacity to estimate multi-level, mixed, and hierarchical regression models with binary or ordinal dependent variables and possible latent (unobserved) variables and random effects at any level. The Newton-Raphson algorithm is implemented in gllamm to calculate maximum likelihood using first and second derivatives (Skrondal and Rabe-Hesketh 2003). The best way to integrate the random effects, in order to obtain the marginal response distribution, is using the Gaussian adaptive quadrature (GAQ) method, which improves the robustness of the results when working with large numbers of observations and between-group correlation (Rabe-Hesketh, Skrondal and Pickles 2004). The Huber/White/sandwich estimator is used to estimate the matrix of covariance of the estimated parameter to obtain a robust variance and adjusted between-group correlation coefficients.

\footnotetext{
${ }^{4}$ Stata. is a statistical tool covering advanced techniques, such as survival models, dynamic panel data (DPD) regressions, generalized estimating equations (GEE), multilevel mixed models, linear and generalized linear models (GLM), regressions with count or binary outcomes, ANOVA/MANOVA, ARIMA, cluster analysis, etc.. For further information see www.stata.com
} 


\section{Results}

Table 1 gives the descriptive statistics and correlations of the variables used in the models. As the table shows, most of the firms (38\% approx.) belong to the high-tech sectors; the next group are the firms from the low-tech sector (36\%) and the last are those from the medium-tech sector (25\%). The average age of the firms is high (about 35 years).

\section{[Insert Table 1]}

With respect to average funding received, a few remarks are due regarding the data in Table 2 , which, unlike those in the previous table, are expressed in thousands of Euros rather than Neperian logs. The means and standard deviations shown on the left-hand side of Table 2 refer to the whole sample of firms, receivers and non-receivers of funding alike, while the figures that appear on the righthand side of the table refer exclusively to receivers, thus enabling us to calculate average funding received.

[Insert Table 2] 
Focusing on those firms that received funding, it can be seen that the most frequent source is the State (582 assignations in all). It is also the most generous, with a mean payout of nearly 360 thousand Euros. The next most frequent sources are the Regional funding (375 assignations). Other sources, including the European Union, come last with 246 assignations. In terms of mean amounts, other sources surpass the Regional funding. These results are in line with those obtained (also for the Spanish context) by Blanes and Busom (2004).

The results of the estimation of equation (1) are given in Table 3.

We perform our first estimation, leaving no $R \& D$ as a reference category. Thus, the results that appear in the first three columns of Table 3 shows that, when taking $n o R \& D$ as a reference, $\mathrm{R} \& \mathrm{D}$ funding, whether it is from the Regional (RF), State (SF) or any other public (OF) body, has a positive effect in that it is associated more strongly with the make, buy or the combined make-buy $\mathrm{R} \& \mathrm{D}$ strategies than with the no $R \& D$ strategy. In other words, the receipt of $\mathrm{R} \& \mathrm{D}$ funding, as might be expected, encourages any R\&D strategy. But, aiming to answering our question whether the source determine the strategy we re-estimate the model changing the reference variable twice for make and buy instead of no $R \& D$, as can be observed for models (4), (5) and (6) of Table $3^{5}$. The purpose of this was to test for significant differences between the estimated coefficients and the coefficients for the reference category in each case.

As the data show, Regional funding appears to increase the firm's probability of selecting the combined make-buy strategy rather than the make strategy, but no significant differences can be observed between make versus buy or make-buy versus buy. Thus, Regional funding appears to make a

\footnotetext{
${ }^{5}$ Estimates of the re-estimation are only presented for those strategies not already included in the previous estimations.
} 
firm slightly more likely to adopt the combined strategy than to opt for in-house R\&D alone, but makes no difference otherwise.

State funding, meanwhile, increases the firm's probability of selecting the combined make-buy strategy rather than either of the others. This finding is in-line with that of Steyer (2006) where, following participation in a State program, firms could be seen to increase their external R\&D expenditure by up to $22 \%$, which places them by our criteria in the combined make-buy category.

Finally, the receipt of aid from other sources, including the European Union, increases the firm's probability of selecting either of the other two strategies rather than the buy strategy on its own. This result may be consonant with the typology of European projects, which are undertaken on a cooperative basis and therefore require participating firms to perform in-house $\mathrm{R} \& \mathrm{D}$ and not rely on outsourcing alone.

\section{[Insert Table 3]}

If we look more closely at the potential medium-term effect $(t-1)$ of receiving $R \& D$ funding, the outcome appears to vary according to the source of the funding. First, Regional funding seems not to have any effect on the R\&D strategy selection. State fund has a medium-term effect on their probability of performing R\&D activities. This fund incentives firms in selecting any of the R\&D strategies and seems to foster the selection of the make-buy strategy over make. However, there seems not to be a difference between make and buy. Regarding the other funding, at $\mathrm{t}-1$ interesting results appear since the make-buy strategy is preferred over buy but the make is preferred over make-buy and buy.

The long-term effect (t-2) of the public R\&D funding seems to be limited to the Regional and State funding. This is interesting because we might have expected a larger effect of the State fund due to the higher amount they financed but the Regional fund has a stronger presence in the long term. It is important to highlight that both found affect in prompting the adoption of the make-buy strategy over the others. 
In conclusion therefore, we find that the duration of the effects of financial aid on the choice of R\&D strategy depends on the source. The reason for the variation may have to do with the objectives the funding is meant to target, which, as we have already mentioned, are not always the same. Thus, Regional funding, who tend to be the least selective when deciding which firms to support and also to assign lower mean amounts, has a contemporaneous and large-effect impact on R\&D selection. In both contemporaneous and long-term effect seems to encourage firms in selecting the make-buy strategy rather than the make, but distinction is between make-buy and buy. State aid, involving higher mean amounts, increase the probability for selecting the complementarity strategy at a contemporaneous, medium- and long-term effect.

Finally, funding from other sources, including the European Union, has no long-term impact. Our results suggest that these sources, which provide funding for cooperative projects, do not encourage the adoption of the buy strategy, which, according to the evidence we have analyzed, has the least demonstrable, sometimes negative, impact on innovation output.

Our findings from the control variables show that the higher the technological intensity of the sector, the greater the firm's probability of adopting some R\&D strategy, but none more than any other. In terms of the workforce skills level, a higher proportion of engineers and graduates among its employees makes a firm more likely to opt for $R \& D$ versus no $R \& D$, while also increasing the probability of selecting make and buy versus make. We also find a significant, positive impact of firm size on the probability of selecting the make-buy strategy versus either of the other two and the buy strategy versus no $R \& D$. Finally, we obtain that the probability of selecting the buy strategy increases with firm age.

\section{Conclusions}


This paper fits into the literature on the effect of public R\&D funding for businesses. Its specific aim is to examine various sources of public funding from the behavioural perspective to investigate their impact on firms' R\&D strategy selection and measure the possible effect over time.

While most previous literature studies the different impact of various R\&D strategy options (make, buy and make-buy) have on innovation output, this study has enabled us to detect whether public institutions are fostering innovation $R \& D$ strategies according to its objectives pursued, and to assess whether public subsidies have a short- or long-term effect on commercial R\&D activities.

The first significant conclusion emerging from this paper is that the source of the funding determines whether R\&D support has only a contemporaneous or a more longer-term effect. Thus, the impact of State aid lasts for two or three periods, depending on the firm's choice of R\&D strategy,. One possibility is that the State may be directing its grants, which involve the largest sums of money, to larger-scale projects, based on the observation that the impact extends beyond two years after receipt of the funding. Another is that the State may be more successful at providing firms with the means to develop their R\&D capacity through the make-buy strategy.

The second important finding from this study is that public funding for R\&Ds, by definition, not just another factor influencing firms' decisions to undertake the type of activities that will enhance their innovation output. We have been able to confirm that the source of the funding is one of the factors that determines the firm's choice of R\&D strategy, that is, whether it opts for in-house $R \& D$, outsourced R\&D or a combination of the two, a decision that will have an impact on its innovation performance.

Specifically, our results show that State funding encourages firms to opt for the make-buy strategy, which, despite being strongly supported by the absorption capacity and open innovation theories,. Regional () funding, the least significant in terms of the sums involved, presents a less obvious pattern, although there is some indication that it encourages selection of the make-buy strategy as opposed to an exclusive make strategy. A possible explanation for this result might lie in the 
diversity of conditions resulting from the decisions of 17 different Regional governments. Finally, the receipt of aid from other organizations, including the European Union, increase the firm's probability of adopting any R\&D strategy, but the buy R\&D strategy has the lowest probability to be selected This suggests that EU funding is having more effect as an incentive to perform in-house $R \& D$, either exclusively or as a complement to technology outsourcing. This is consistent with the objectives and typology of European projects, which, being organized on a cooperative basis, require each participating firm to perform some activities in-house.

This study has certain limitations deriving, among other factors, from the use of a database not specifically designed for our research objective. For example, the fact that we identify each firm's adopted R\&D strategy based on its responses in the SBSS may compromise our findings somewhat, because we cannot know whether the respondent fully understood the distinction between innovation strategy and $R \& D$ strategy; nor are we in possession of data regarding the main purposes for which the funds are used. Finally, the main limitation of this study is that the results and conclusions draw in this study comes from a specific sample and they only apply for large Spanish manufacturing firms. In order to draw general conclusions, further studies need to be developed. 


\section{References}

Almus, M., and D. Czarnitkki. 2003. The effects of public R\&D subsidies on firms' innovation activities: the case of Eastern Germany. Journal of Business \& Economic Statistics 21: 226-36.

Acosta, J. and A. Modrego. 2001. Public financing of cooperative R\&D projects in Spain: the concerted projects under the National R\&D Plan. Research Policy 30: 625-41

Baumol, W. 2002. The free market innovation machine: Analyzing the growth miracle of Capitalism. Princeton University Press, Princeton.

Bayona-Saéz, C. and T. Garcia-Marco. 2010. Assessing the effectiveness of the Eureka Program. Research Policy 39: 1375-86.

Beneito, P., 2006. The innovative performance of in-house and contracted R\&D in terms of patents and utility models. Research Policy 35: 502-37.

Benfratello, L., and A. Sembenelli. 2002. Research joint ventures and firm level performance. Research Policy, 31: 493-507.

Blanes, J.V., and I. Busom. 2004. Who participates in R\&D subsidy programs? The case of Spanish manufacturing firms. Research Policy 33:1459-76.

Branstetter, L. and M. Sakakibara. 1998. Japanese research consortia: a microeconometric analysis of industrial policy. The Journal of Industrial Economics 56: 207-33.

Chen, Y., and Y. Yuan. 2007. The innovation strategy of firms: empirical evidence from the Chinese high-tech industry. Journal of Technology Management in China 2: 145-53.

. Cruz-Cazares, C., C. Bayona-Sáez, and T. García-Marco. 2010. R\&D Strategies and Firm Innovative Performance: A Panel Data Analysis. International Journal of Innovation Management 14: $1013-45$ 
Cho, D., and P. Yu. 2000. Influential factors in the choice of technology acquisition mode: In empirical analysis of small and medium size firms in the Korean telecommunication industry. Technovation 20: 691-704.

David, P., H. Bronwyn, and A. Toole. 2000. Is public R\&D a complement or substitute for private R\&D? A review of the econometric evidence. Research Policy 29: 497-529

Department of Industry, Tourism and Resources of Australia. 2006. Behavioural additionality of Business R\&D grant programmes in Australia. In Government $R \& D$ funding and company behaviour. Measuring behavioural additionality. OECD, 2006, 39-57

Díaz-Díaz, N.L., I. Aguiar-Díaz, and P. De Saá-Pérez. 2008. The effect of technological knowledge assets on performance: The innovative choice in Spanish firms. Research Policy 37: 1515-29.

Falk, R. 2006. Behavioural additionality of Austria's industrial research promotion fund (FFF). In Government $R \& D$ funding and company behaviour. Measuring behavioural additionality. OECD, 2006, 59-74.

Fariñas, J.C., and J. Jaumandreu (2000). Diez años de Encuesta sobre Estrategias Empresariales (ESEE). Economía Industrial 329: 29-42.

Fey, C.F., and J. Birkinshaw. 2005. External sources of knowledge, governance mode, and R\&D Performance. Journal of Management 31: 597-621

García-Quevedo, J. 2004. Do public subsidies complement business R\&D? A Meta-Analysis of the econometric evidence. Kyklos 57: 87-102

Georghiou, L., and D. Roessner. 2000. Evaluating technology programs: tools and methods. Research Policy 29: 657-78

Georghiou, L., and B. Clarysse. 2006. Introduction and Synthesis. In Government R\&D funding and company behaviour. Measuring behavioural additionality. OECD, 2006, 9-38 
Haro-Dominguez, M.C., D. Arias-Aranda, F.J. Lloréns-Montes, and A. Ruiz, 2007. The impact of absorptive capacity on technological acquisitions engineering consulting companies. Technovation 27: 417-25.

Heijs, J., L. Herrera, M. Buesa, J. Sáiz, and P. Valadez. 2005. Efectividad de la política de cooperación en innovación: evidencia empírica española. Papeles de Trabajo $\mathrm{N}^{\mathrm{o}} 1 / 05$ del Instituto de Estudios Fiscales.

Hsiao, C. 1985. Benefits and limitations of panel data. Econometric Review 4: 121-74.

Huggins, R. 2001. Inter-firm network policies and firm performance: evaluating the impact of initiatives in the United Kingdom. Research Policy 30: 443-58

Hyvärinen, J. 2006. Behavioural additionality of public R\&D funding in Finland. In Government R\&D funding and company behaviour. Measuring behavioural additionality. OECD, 2006, 115-126.

Jaffe, A. 2002. Building programme evaluation into the design of public research-support programmes. Oxford Review of Economic Policy 18: 22-34.

Jones, G.K., A. Lanctot, and H.J. Teegen. 2001. Determinants and performance impacts of external technology acquisition. Journal of Business Venturing 16: 255-83.

Kessler, E.H., P.E. Bierly, and S. Gopalakrishnan. 2000. Internal vs. external learning in new product development: Effects on speed, cost and competitive advantage. $R \& D$ Management 30: 213-23.

Klette, T.J, and J. Moen. 1999. From growth theory to technology policy - coordination problems in theory and practice. Nordic Journal of Political Economy 25: 53-74

Klette, T.J., J. Moen, and Z. Griliches. 2000. Do subsidies to commercial R\&D reduce market failures? Microeconometric evaluation studies. Research Policy 29: 471-95.

Lanctot A., and S.K. Swan. 2000. Technology acquisition strategy in an internationally competitive environment. Journal of International Management 6: 187-215. 
Lööf, H., and A. Hesmati. 2005. The impact of public funding on private R\&D investment. New evidence from a firm level innovation study. CESIS, Electronic Working Paper Series.

Luukkonen, T. 2000. Additionality of EU framework programmes. Research Policy 29: 711-24.

Mol, M.J. 2005. Does being R\&D intensive still discourage outsourcing? Evidence from Dutch manufacturing. Research Policy 34: 571-82.

OECD. 1997. Proposed guidelines for collecting and interpreting technological innovation data: Oslo manual. OECD, Paris (Second (revised) Edition).

OECD. 2006. Government $R \& D$ funding and company behaviour. Measuring behavioural additionality. OECD, 2006.

Parmigiani, A. 2007. Why do firms both make and buy? An investigation of current sourcing. Strategic Management Journal 28: 285-311.

Polt, W., and G. Streicher. 2005. Trying to capture additionality in Framework Programme 5 - main findings. Science and Public Policy 32: 367-73.

Rabe-Hesketh, S., A. Skrondal, and A. Pickles .2004. GLLAMM Manual. U.C. Berkeley Division of $\begin{array}{lllll}\text { Biostatistics Working } & \text { Paper }\end{array}$ http://www.bepress.com/ucbbiostat/paper160

Roper, S., N. Hewitt-Dundas, and J. Love. 2004. An ex ante evaluation framework for the regionalbenefits of publicly supported R\&D projects. Research Policy 33: 487-509.

Salter, A., and B. Martin. 2001. The economic benefits of publicly funded basic research: a critical review. Research Policy 30: 509-32

Santamaría, L., M.J. Nieto, and A. Barge-Gil. 2009. Beyond formal R\&D: Taking advantage of other sources of innovation in low- and medium-technology industries. Research Policy 38: 507-17. 
Schmiedeberg, C. 2008. Complementarities of innovation activities: An empirical analysis of the German manufacturing sector. Research Policy 37: 1492-1503.

Skrondal, A., and S. Rabe-Hesketh 2003. Multilevel logistic regression for polytomous data and rankings. Psychometrika 68: 267-287.

Steyer, F. 2006. Behavioural additionality in Austria's K-Plus competence centre programme. In Government R\&D funding and company behaviour. Measuring behavioural additionality. OECD, 2006, 75-89.

Tsai K., and J. Wang. 2009. External technology sourcing and innovation performance in LMT sectors: An analysis based on the Taiwanese Technological Innovation Survey. Research Policy 38: 518-26.

Veugelers, R., and B. Cassiman. 1999. Make and buy in innovation strategies: Evidence from Belgian manufacturing firms. Research Policy 28: 63-79.

Veugelers, R., and B. Cassiman, 2006. In search of complementarity in innovation strategy: Internal R\&D and external knowledge acquisition. Management Science 52: 68-82. 
Table 1. Means, standard deviations and correlations among variables

\begin{tabular}{|c|c|c|c|c|c|c|c|c|c|c|c|c|}
\hline Variable & Mean & Std.Dev & RDS & $\mathbf{R F}_{\mathbf{t}}$ & $\mathbf{S F}_{\mathbf{t}}$ & $\mathbf{O F}_{\mathbf{t}}$ & LTI & MTI & HTI & GP & SIZE & AGE \\
\hline RDS & 2.3697 & 1.1644 & 1 & & & & & & & & & \\
\hline $\mathbf{R F}_{\mathbf{t}}$ & 0.3993 & 1.3004 & $0.2568 *$ & 1 & & & & & & & & \\
\hline $\mathbf{S F}_{\mathbf{t}}$ & 0.7068 & 1.7828 & $0.2812 *$ & $0.3410 *$ & 1 & & & & & & & \\
\hline $\mathrm{OF}_{\mathrm{t}}$ & 0.2813 & 1.1456 & $0.1284 *$ & $0.2111^{*}$ & $0.2612 *$ & 1 & & & & & & \\
\hline LTI & 0.3623 & 0.4807 & $-0.2108^{*}$ & $-0.1519 *$ & $-0.1669 *$ & $-0.1052 *$ & 1 & & & & & \\
\hline MTI & 0.2552 & 0.436 & 0.018 & 0.025 & 0.0116 & 0.0318 & $-0.4413^{*}$ & 1 & & & & \\
\hline HTI & 0.3823 & 0.486 & $0.1923 *$ & $0.1278^{*}$ & $0.1547^{*}$ & $0.0755^{*}$ & $-0.5931 *$ & $-0.4607 *$ & 1 & & & \\
\hline GP & 6.2022 & 7.5099 & $0.1669 *$ & 0.0391 & $0.1933^{*}$ & $0.0708^{*}$ & $-0.1253^{*}$ & $-0.1457 *$ & $0.2546^{*}$ & 1 & & \\
\hline SIZE & 18.04 & 1.0728 & $0.1391 *$ & 0.0427 & $0.1248^{*}$ & $0.0887 *$ & $-0.0972 *$ & -0.0416 & $0.1335^{*}$ & $0.2764 *$ & 1 & \\
\hline AGE & 35.851 & 25.6966 & 0.0255 & -0.0278 & 0.0385 & -0.0327 & $0.0776^{*}$ & $-0.0611 *$ & -0.0219 & $0.1319 *$ & $0.0896^{*}$ & 1 \\
\hline
\end{tabular}

* p> 0.00

\begin{tabular}{|c|c|c|c|c|c|c|}
\hline & \multicolumn{3}{|c|}{ Total number of firms } & \multicolumn{3}{|c|}{ Firms that received funding } \\
\hline & Observations & Mean & $\begin{array}{l}\text { Standard } \\
\text { deviation }\end{array}$ & Observations & Mean & $\begin{array}{l}\text { Standard } \\
\text { deviation }\end{array}$ \\
\hline$R F^{*}$ & 3941 & 15.50 & 101.02 & 375 & 162.91 & 288.86 \\
\hline$S F^{*}$ & 3941 & 53.11 & 410.10 & 582 & 359.63 & 1014.93 \\
\hline$O F^{*}$ & 3941 & 14.56 & 129.41 & 246 & 233.25 & 467.01 \\
\hline
\end{tabular}

* Thousands of Euros 


\begin{tabular}{|c|c|c|c|c|c|c|c|}
\hline \multirow{2}{*}{\multicolumn{2}{|c|}{$\begin{array}{c}\text { Table } 3 \\
\text { Variables }\end{array}$}} & \multirow{2}{*}{\multicolumn{6}{|c|}{ R\&D Strategies }} \\
\hline & & & & & & & \\
\hline & & \multirow{2}{*}{$\begin{array}{c}\begin{array}{c}\text { Make } \\
(\mathbf{1})\end{array} \\
1.3696^{*} \\
(0.728) \\
0.9826^{* * *} \\
(0.288) \\
2.4342^{* * *} \\
(0.000)\end{array}$} & \multirow{2}{*}{$\begin{array}{c}\begin{array}{c}\text { Buy } \\
(2)\end{array} \\
1.4256^{*} \\
(0.737) \\
0.8446^{* * *} \\
(0.297) \\
2.0770^{* * * *} \\
(0.505)\end{array}$} & \multirow{2}{*}{$\begin{array}{c}\begin{array}{c}\text { Make-Buy } \\
(3)\end{array} \\
1.4930^{* *} \\
(0.728) \\
1.0543^{* * *} \\
(0.289) \\
2.3697^{* * *} \\
(0.478) \\
\end{array}$} & \multirow{2}{*}{$\begin{array}{c}\begin{array}{c}\text { Buy } \\
(4)\end{array} \\
0.0500 \\
(0.072) \\
-0.1115 \\
(0.077) \\
-0.3364^{* * *} \\
(0.111)\end{array}$} & \multirow{2}{*}{$\begin{array}{c}\text { Make-Buy (5) } \\
0.1359^{* *} \\
(0.054) \\
0.1040^{* * *} \\
(0.038) \\
-0.0018 \\
(0.035)\end{array}$} & $\begin{array}{c}\text { Buy as reference } \\
\text { variable } \\
\text { Make-Buy } \\
\text { (6) }\end{array}$ \\
\hline Funding & $\begin{array}{l}R F_{t} \\
S F_{t} \\
O F_{t}\end{array}$ & & & & & & $\begin{array}{c}0.0005 \\
(0.078) \\
0.2186^{* *} \\
(0.107) \\
0.3064^{* * *} \\
(0.069)\end{array}$ \\
\hline Funding -1 & $\begin{array}{l}R F_{t-1} \\
S F_{t-1} \\
O F_{t-1}\end{array}$ & $\begin{array}{c}0.1359 \\
(0.174) \\
0.3287^{* *} \\
(0.151) \\
0.1327 \\
(0.207)\end{array}$ & $\begin{array}{c}0.1471 \\
(0.184) \\
0.3076^{* *} \\
(0.155) \\
-0.0830 \\
(0.225)\end{array}$ & $\begin{array}{l}0.1893 \\
(0.176) \\
0.3687^{* * *} \\
(0.150) \\
0.0869 \\
(0.209)\end{array}$ & $\begin{array}{c}-0.0011 \\
(0.070) \\
-0.0103 \\
(0.058) \\
-0.2335^{* * *} \\
(0.086)\end{array}$ & $\begin{array}{c}0.0390(0.049) \\
0.0550^{*} \\
(0.031) \\
-0.0548^{*} \\
(0.032)\end{array}$ & $\begin{array}{l}0.0279 \\
(0.085) \\
0.0173 \\
(0.073) \\
0.1784^{* *} \\
(0.083)\end{array}$ \\
\hline $\begin{array}{l}\text { Technological } \\
\text { Intensity }\end{array}$ & $\begin{array}{l}\text { MIT } \\
\text { HIT }\end{array}$ & $\begin{array}{l}0.9865^{*} \\
(0.543) \\
2.3373^{* * *} \\
(0.539)\end{array}$ & $\begin{array}{l}1.4414^{* * * *} \\
(0.554) \\
2.5886^{* * * *} \\
(0.564)\end{array}$ & $\begin{array}{l}1.2756^{* *} \\
(0.558) \\
2.4820^{* * * *} \\
(0.552)\end{array}$ & $\begin{array}{l}0.4051 \\
(0.464) \\
-0.2008 \\
(0.420)\end{array}$ & $\begin{array}{l}0.1710 \\
(0.336) \\
-0.2530 \\
(0.318)\end{array}$ & $\begin{array}{l}-0.5734 \\
(0.464) \\
-0.1742 \\
(0.431)\end{array}$ \\
\hline \multirow[t]{3}{*}{$\begin{array}{l}\text { Percentage of } \\
\text { Graduates }\end{array}$} & $G P$ & $\begin{array}{l}0.0574^{*} \\
(0.031)\end{array}$ & $\begin{array}{c}0.0608^{* *} \\
(0.033)\end{array}$ & $\begin{array}{c}0.0741^{* *} \\
(0.030)\end{array}$ & $\begin{array}{l}0.0247 \\
(0.025)\end{array}$ & $\begin{array}{c}0.0345^{* *} \\
(0.017)\end{array}$ & $\begin{array}{l}0.0006 \\
(0.029)\end{array}$ \\
\hline & Size & $\begin{array}{c}0.7471 * * * \\
(0.226)\end{array}$ & $\begin{array}{c}0.8997^{* * *} \\
(0.238)\end{array}$ & $\begin{array}{c}0.8354^{*} * * \\
(0.229)\end{array}$ & $\begin{array}{c}0.02340 \\
(0.302) \\
\end{array}$ & $\begin{array}{l}-0.0735 \\
(0.251) \\
\end{array}$ & $\begin{array}{l}0.0329 \\
(0.625) \\
\end{array}$ \\
\hline & Age & $\begin{array}{l}0.0012 \\
(0.007)\end{array}$ & $\begin{array}{l}-0.0115 \\
(0.008)\end{array}$ & $\begin{array}{l}0.0025 \\
(0.007)\end{array}$ & $\begin{array}{c}-0.0140^{* *} \\
(0.007)\end{array}$ & $\begin{array}{l}-0.0007 \\
(0.004)\end{array}$ & $\begin{array}{l}0.013^{* *} \\
(0.006)\end{array}$ \\
\hline
\end{tabular}


